\title{
Assessments of endothelial function and arterial stiffness are reproducible in patients with COPD
}

\author{
This article was published in the following Dove Press journal: \\ International Journal of COPD \\ 16 September 2015 \\ Number of times this article has been viewed
}

\author{
Paula Rodriguez-Miguelez' \\ Nichole Seigler' \\ Leon Bass ${ }^{2}$ \\ Thomas A Dillard ${ }^{2}$ \\ Ryan A Harris ${ }^{1,3}$
}

'Division of Clinical and Translational Sciences, Georgia Prevention Institute, Georgia Regents University, Augusta, GA, USA; ${ }^{2}$ Pulmonary and Critical

Care Medicine, Department of Medicine, Georgia Regents University, Augusta, GA, USA; ${ }^{3}$ Sport and Exercise Science Research Institute, University of Ulster, Jordanstown, Northern Ireland, UK
Background: Elevated cardiovascular disease risk is observed in patients with COPD. Non-invasive assessments of endothelial dysfunction and arterial stiffness have recently emerged to provide mechanistic insight into cardiovascular disease risk in COPD; however, the reproducibility of endothelial function and arterial stiffness has yet to be investigated in this patient population.

Objectives: This study sought to examine the within-day and between-day reproducibility of endothelial function and arterial stiffness in patients with COPD.

Methods: Baseline diameter, peak diameter, flow-mediated dilation, augmentation index, augmentation index at 75 beats per minute, and pulse wave velocity were assessed three times in 17 patients with COPD (six males, eleven females, age range 47-75 years old; forced expiratory volume in 1 second $=51.5 \%$ predicted). Session A and B were separated by 3 hours (withinday), whereas session $\mathrm{C}$ was conducted at least 7 days following session $\mathrm{B}$ (between-day). Reproducibility was assessed by: 1) paired $t$-tests, 2) coefficients of variation, 3 ) coefficients of variation prime, 4) intra-class correlation coefficient, 5) Pearson's correlations ( $r$ ), and 6) Bland-Altman plots. Five acceptable assessments were required to confirm reproducibility.

Results: Six out of six within-day criteria were met for endothelial function and arterial stiffness outcomes. Six out of six between-day criteria were met for baseline and peak diameter, augmentation index and pulse wave velocity, whereas five out of six criteria were met for flow-mediated dilation.

Conclusion: The present study provides evidence for within-day and between-day reproducibility of endothelial function and arterial stiffness in patients with COPD.

Keywords: arterial stiffness, endothelial function, flow-mediated dilation, pulse-wave velocity, chronic obstructive pulmonary disease

\section{Introduction}

COPD, the third leading cause of morbidity and mortality worldwide, is a progressive disease of the lungs that is characterized by a persistent airflow limitation. ${ }^{1}$ Common phenotypes observed in patients with COPD are chronic inflammation and oxidative stress, systemic consequences that appear to contribute to an augmented cardiovascular mortality risk in these patients. ${ }^{2-4}$

More patients with COPD die from cardiovascular disease and coronary heart disease than of direct pulmonary complications. ${ }^{5}$ Although the pathogenic mechanism that links COPD to vascular related diseases is poorly understood, data have supported the potential contribution of vascular endothelial dysfunction. ${ }^{4,6}$ In fact, the degree of endothelial dysfunction is proportional with disease severity measured by airway obstruction. ${ }^{2,7}$ Accordingly, the assessment of vascular function represents an important clinical outcome in the ongoing investigation of the pathophysiology of COPD.
Correspondence: Ryan A Harris Georgia Prevention Institute, Georgia Regents University, II 20 I5th Street, HS-1707, Augusta, GA 30912, USA

Tel +l $70672 I 5998$

Fax +I 7067217150

Email ryharris@gru.edu 
The flow-mediated dilation (FMD) test is the most widely utilized, non-invasive assessment of nitric oxide bioavailability and vascular endothelial function in humans. Additionally, augmentation index (AIx) and pulse wave velocity (PWV) represent two non-invasive methods for assessing aortic and central arterial stiffness, respectively. A lower FMD strongly correlates with vascular damage, ${ }^{8}$ and both FMD and PWV have been shown to be independent predictors of cardiovascular disease. ${ }^{9,10}$ In fact, numerous investigations have described how the FMD test can be utilized to provide prognostic information of cardiovascular disease related risk. ${ }^{11-15}$ Unsurprisingly, both $\mathrm{FMD}^{2,16-18}$ and PWV ${ }^{10,19}$ have been reported to be attenuated in patients with COPD compared with age-matched controls. In addition, our group has recently identified oxidative stress as a contributing mechanism to this associated vascular dysfunction. ${ }^{18}$

Since the awareness of cardiovascular disease risk in patients with COPD is growing, we are anticipating more investigations of endothelial function and arterial stiffness in this patient population. There are however, several biological and environmental aspects of COPD that may impact the reliability of these non-invasive techniques. ${ }^{20}$ Thus, the purpose of this study was to evaluate the within-day and between-day reproducibility of FMD and arterial stiffness in patients with COPD. We hypothesized that repeated assessments of FMD and arterial stiffness in the same day and on different days would be similar in patients with COPD.

\section{Methodology Experimental design}

All patients with COPD reported to the Laboratory of Integrative and Vascular Exercise Physiology on two experimental visits separated by at least 1 week apart. On the first visit, a pulmonary function testing (PFT) was performed and FMD, PWV, and AIx were assessed twice, 3 hours apart, to determine within-day reproducibility of endothelial function and arterial stiffness. At least 1 week following visit 1 , patients reported back to the Laboratory of Integrative and Vascular Exercise Physiology where the same assessments were repeated to determine between-day reproducibility of endothelial function and arterial stiffness. Patients were asked to abstain from physical activity, tobacco products for at least 12 hours, and vitamin supplementation for 72 hours prior to each session visit.

\section{Subjects}

Seventeen patients with COPD (six males, eleven females, age range $47-75$ years) volunteered to participate in the study. Patients were excluded from the study if: 1) forced expiratory volume in 1 second $\left(\mathrm{FEV}_{1}\right)$ /forced vital capacity (FVC) was $>0.7,2) \mathrm{FEV}_{1}$ was $>80 \%, 3$ ) they had evidence of overt heart disease, diabetes, gastrointestinal bleeding or pulmonary hypertension, or 4) they were taking any medications known to affect the FMD response. All participants were informed of the objectives and possible risks of the investigation before written consent for participation was obtained. The study followed the principles of the Declaration of Helsinki and was approved by the Institutional Review Board at Georgia Regents University.

\section{Pulmonary function testing}

A PFT using closed circuit spirometry (ParvoMedics, Sandy, UT, USA) was performed to determine FVC, FEV ${ }_{1}$, $\mathrm{FVC} / \mathrm{FEV}_{1}$, and forced expiratory flow $\left(\mathrm{FEF}_{25-75}\right)$ in all patients according to the American Thoracic Society standards. ${ }^{21}$ Additional PFT methodology can be found in the Supplementary materials.

\section{Brachial artery FMD}

Endothelial function was determined via brachial artery FMD in accordance with the latest tutorial on the ultrasound assessment of FMD. ${ }^{22}$ Additional FMD methodology can be found in the Supplementary materials.

\section{Arterial tonometry Pulse wave analysis}

AIx was determined by applanation tonometry (SphygmoCor; AtCor Medical, West Ryde, Australia) of the left radial artery, calibrated with the brachial systolic and diastolic pressure. Since AIx varies with heart rate, it is adjusted to 75 beats per minute $(\mathrm{AIx} 75){ }^{23}$

\section{PWV}

Carotid-femoral PWV was determined in duplicate using the SphygmoCor system by sequentially recording electrocardiographic-gated carotid and femoral artery waveforms by applanation tonometry. ${ }^{24,25}$ Additional arterial tonometry methodology can be found in the Supplementary materials.

\section{Assessment of reproducibility and statistical analysis}

All measurements are expressed as mean \pm standard error of mean. All statistical analyses were performed using SPSS version 18 (SPSS Inc., Chicago, IL, USA) and significance was set at $P<0.05$. Within-day reproducibility 
was determined by comparing session A vs session B, whereas between-day reproducibility compared session A vs session C. In order to demonstrate reproducibility, five out of the six following criteria were required for each outcome: 1$)$ a non-significant $(P>0.05)$ paired $t$-test, 2$)$ a significant intra-class correlation coefficient (ICC), 3) a significant Pearson's correlation coefficient $(r), 4)$ a coefficient of variation $(\mathrm{CV}=\mathrm{SD} /$ mean $\times 100)$ of $<20 \%$ and $35 \%$ for all variables and FMD, respectively, 5) a $\mathrm{CV}$ prime $\left(\mathrm{CV}^{\prime}=[100 \times \mathrm{SD}] /[\right.$ mean +100$\left.]\right)$ of $<3 \%,{ }^{26}$ and 6) a Bland-Altman plot with only two values accepted outside of the $95 \%$ CI. In addition, analysis of covariance (ANCOVA) for endothelial function and arterial stiffness was conducted using age, race, sex, and cotinine as covariates.

\section{Results \\ Study participants}

Demographic and clinical characteristics of all patients with COPD who participated in this study are presented in Table 1. Majority of the patients (53\%) were classified as Global

Table I Characteristics and blood chemistry of patients with COPD

\begin{tabular}{|c|c|}
\hline Variable & COPD patients \\
\hline $\mathrm{n}$ & 17 \\
\hline Male/female & $6 / 11$ \\
\hline Age (years) & $56 \pm 2$ \\
\hline Height (cm) & $166 \pm 3$ \\
\hline Weight (kg) & $86 \pm 4$ \\
\hline BMI $\left(\mathrm{kg} / \mathrm{m}^{2}\right)$ & $32.0 \pm 1.9$ \\
\hline SBP (mmHg) & $130 \pm 4$ \\
\hline $\mathrm{DBP}(\mathrm{mmHg})$ & $77 \pm 3$ \\
\hline $\mathrm{FEV}_{1}(\mathrm{~L} / \mathrm{min})$ & $1.52 \pm 0.53$ \\
\hline $\mathrm{FEV}_{1}(\%$ predicted $)$ & $51.5 \pm 3.4$ \\
\hline $\mathrm{FEV}_{\mathrm{I}} / \mathrm{FVC}$ ratio (\%) & $54.8 \pm 3.8$ \\
\hline Glucose (mg/dL) & $99 \pm 4$ \\
\hline Total cholesterol (mg/dL) & $203 \pm 13$ \\
\hline HDL cholesterol (mg/dL) & $63 \pm 4$ \\
\hline LDL cholesterol (mg/dL) & $|22 \pm 1|$ \\
\hline Triglycerides (mg/dL) & $124 \pm 16$ \\
\hline Hemoglobin (g/dL) & $14.6 \pm 0.5$ \\
\hline Hematocrit (\%) & $42.1 \pm 1.2$ \\
\hline CRP (mg/L) & $9.3 \pm 2.5$ \\
\hline Ankle brachial pressure index (right) & $1.19 \pm 0.1$ \\
\hline Ankle brachial pressure index (left) & $1 . I \pm 0.1$ \\
\hline Plasma cotinine $(\mathrm{ng} / \mathrm{mL})$ & $103 \pm 30$ \\
\hline Trans-3-hydroxycotinine (ng/mL) & $42 \pm 14$ \\
\hline
\end{tabular}

Note: Data are expressed as mean \pm standard error of mean. Abbreviations: BMI, body mass index; SBP, systolic blood pressure; DBP, diastolic blood pressure; $\mathrm{FEV}_{1}$, forced expiratory volume in I second; $\mathrm{FVC}$, forced vital capacity; HDL, high-density lipoprotein; LDL, low-density lipoprotein.
Initiative for Chronic Obstructive Lung Disease (GOLD) stage 2 , whereas $23 \%$ and $24 \%$ of patients met criteria for stage 1 and 3, respectively. No significant differences in demographic or clinical variables, including changes in PFT, were identified between visits.

\section{Reproducibility of endothelial function}

Within-day (session A and session B) and between-day (session A and session C) assessments of reproducibility of endothelial function are presented in Table 2. Parameters obtained from the FMD test included baseline diameter $(\mathrm{cm})$, peak diameter $(\mathrm{cm})$, and FMD (\%). Individual reproducibility assessments that meet the aforementioned criteria are in bold.

FMD is reproducible within the same day in patients with COPD

Mean values of baseline diameter, peak diameter, and FMD were all similar $(P>0.05)$ between session $\mathrm{A}$ and session B. In addition, all endothelial function testing variables exhibited acceptable CV, $\mathrm{CV}^{\prime}$, and the ICC and Pearson correlation coefficients were all significant $(P<0.03)$. Figure 1 illustrates the within-day (session $A$ and session B) Bland-Altman plots for baseline diameter (Figure 1A), peak diameter (Figure 1B), and FMD (Figure 1C). All points fall within the $95 \% \mathrm{CI}$ for peak diameter and FMD; however, there is only one point that falls outside of the CI for baseline diameter. Taken together, all six within-day reproducibility criteria were met for baseline diameter, peak diameter, and FMD.

\section{FMD is reproducible between-days in patients with COPD}

Mean values of baseline diameter, peak diameter, and FMD were all similar $(P>0.05)$ between session $\mathrm{A}$ and session $\mathrm{C}$. An acceptable $\mathrm{CV}$ and $\mathrm{CV}^{\prime}$ was observed for baseline and peak diameter, but not for FMD (\%). In addition, the ICC and Pearson correlation coefficients were all significant $(P \leq 0.01)$ for all of the endothelial function testing variables. Figure 2 illustrates the between-day (session A and session $\mathrm{C}$ ) Bland-Altman plots for baseline diameter (Figure 2A), peak diameter (Figure 2B), and FMD (Figure 2C). All points fall within the $95 \% \mathrm{CI}$ for FMD; however, there is only one point each that falls outside of the CI for baseline diameter and peak diameter. All six between-day reproducibility criteria were met for baseline diameter and peak diameter, whereas five out of the six criteria were met for FMD. 


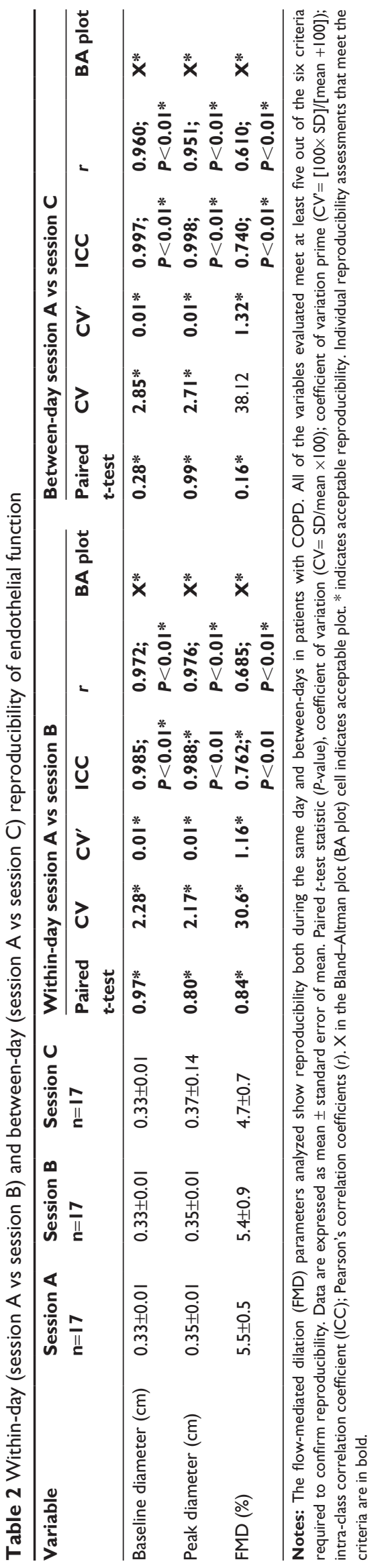

\section{Reproducibility of arterial stiffness}

Within day (session A and session B) and between day (session $\mathrm{A}$ and session $\mathrm{C}$ ) reproducibility of arterial stiffness are presented in Table 3. Parameters of arterial stiffness testing included AIx (\%), AIx75 (\%), and PWV (m/s). Individual reproducibility assessments that meet the aforementioned criteria are in bold.

Arterial stiffness is reproducible within the same day in patients with COPD

Mean values of AIx, AIx75, and PWV were all similar $(P>0.05)$ between session A and session B. In addition, all parameters of arterial stiffness exhibited acceptable $\mathrm{CV}$, $\mathrm{CV}^{\prime}$, and significant ICC and Pearson correlation coefficients $(P \leq 0.01)$. Furthermore, all points fall within the $95 \% \mathrm{CI}$ on the Bland-Altman plot for AIx and AIx75; however, there is one point that falls outside of the CI for PWV (Figure S1). All six within-day reproducibility criteria were met for AIx, AIx75, and PWV.

\section{Arterial stiffness is reproducible between-days in patients with COPD}

No differences in mean AIx, AIx75, and PWV were observed between session A and session $\mathrm{C}$ (all $P>0.05$ ). In addition, all arterial stiffness testing variables exhibited acceptable $\mathrm{CV}, \mathrm{CV}^{\prime}$, and significant ICC and Pearson correlation coefficients $(P \leq 0.01)$. Furthermore, all points fall within the $95 \%$ CI on the Bland-Altman plot for PWV; however, there is one point each that falls outside of the CI for AIx and AIx75 (Figure S2). All six betweenday reproducibility criteria were met for AIx, AIx75, and PWV.

\section{Discussion}

Due to elevated cardiovascular disease risk associated with lung disease, there is emerging interest in conducting clinical trials that target vascular health outcomes in patients with COPD. The present study not only supports within-day, but also between-day reproducibility of vascular health assessments using FMD and arterial tonometry in patients with COPD. These findings are particularly important when evaluating the potential mechanisms that contribute to cardiovascular disease risk in COPD, either in a single testing day or over a longer treatment period.

Patients with COPD present a high risk of cardiovascular disease associated with the disturbance of the vascular endothelium. ${ }^{2,718}$ Local inflammation in respiratory airways induces the over production of reactive oxygen species, 
A

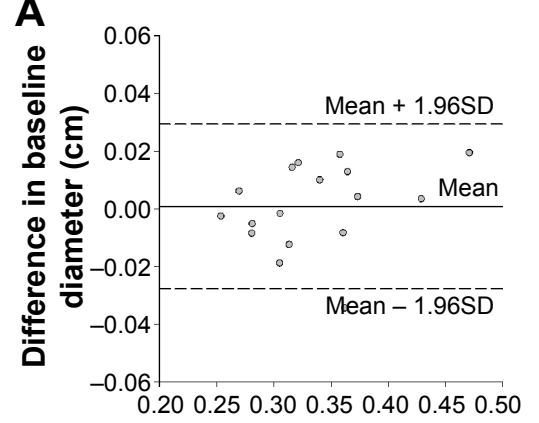

Mean baseline diameter $(\mathrm{cm})$
B

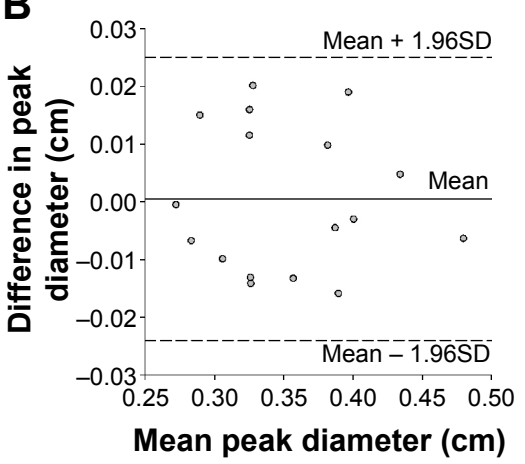

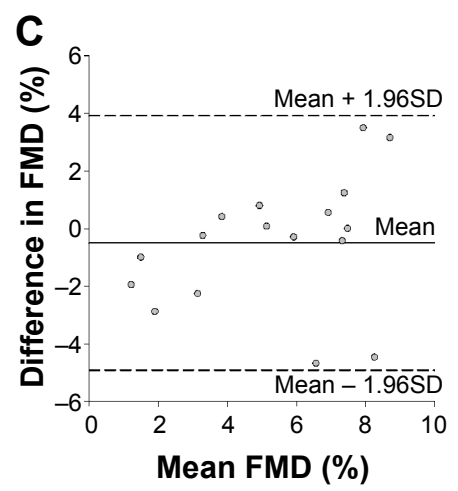

Figure I Bland-Altman analysis plots illustrating no systematic bias and good within-day reproducibility.

Notes: Within-day (session A and session B) Bland-Altman plots for (A) baseline diameter, (B) peak diameter, and (C) flow-mediated dilation (FMD). Patients with COPD underwent two examinations during the same day ( 3 hours apart) to confirm within-day reproducibility of endothelial function. The $x$-axis shows the mean of each variable and the $y$-axis the difference between pairs. Solid lines represent systematic bias and dashed lines represent the $95 \% \mathrm{Cl}$ at two SD of the differences.

chemokines, and cytokines which evoke a systemic perturbation that reduces nitric oxide bioavailability and contributes to systemic vascular dysfunction. ${ }^{18,27}$ In fact, the degree of endothelial impairment is not only related with disease severity assessed by $\mathrm{FEV}_{1}(\%$ predicted), but is also associated with a worse overall prognosis..$^{2,17,28} \mathrm{In}$ an effort to control for the impact of pulmonary exacerbation throughout the present investigation, it is important to emphasize that no changes in pulmonary function were observed in the patients across the multiple testing sessions.

\section{Vascular health reproducibility criteria}

Studies in the field suggest the use of three variability indices as an approach to establish consistency and standardization of the technique and provide an accurate assessment of reproducibility. For the current study we included the mean differences between sessions, the CV, and Pearson's correlations which have been previously recommended, ${ }^{29,30}$ however, we also included CV', ICC, and Bland-Altman plots to provide a more robust assessment of vascular health reproducibility in patients with COPD.

\section{Reproducibility of endothelial function in COPD}

Since 1992, the FMD test has been widely utilized as a non-invasive method to evaluate systemic vascular endothelial function $^{31}$ and predict future cardiovascular disease and events in humans. ${ }^{22}$ The assessment of endothelial function with FMD has been shown to correlate with other invasive techniques, ${ }^{32}$ thus asserting the utility that this procedure presents for a non-invasive and fast peripheral artery function evaluation. Indeed, our group and others have contributed to the overall consensus that the FMD test is in fact, a reproducible technique in healthy adults. ${ }^{26,33,34}$ It is important to note; however, that some studies have described low consistency in the stability of brachial artery FMD, ${ }^{35,36}$ whereas others have reported high reproducibility. ${ }^{20,30,37-39}$ Nonetheless, this
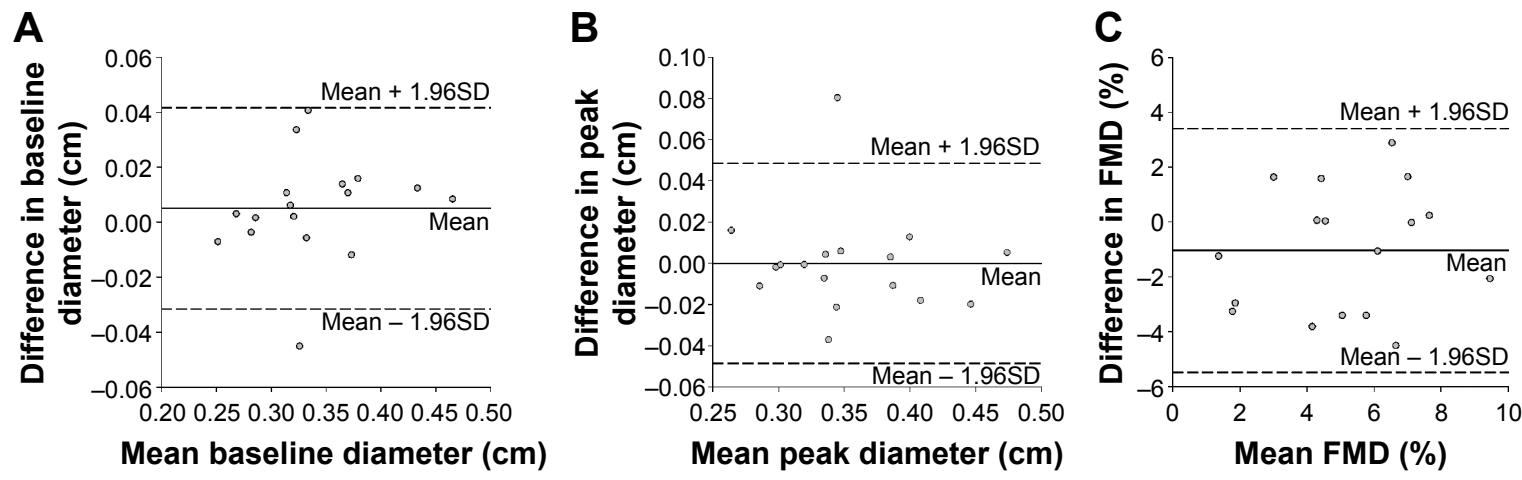

Figure 2 Bland-Altman analysis plots illustrating no systematic bias and good between-day reproducibility.

Notes: Between-day (session A and session C) Bland-Altman plots for (A) baseline diameter, (B) peak diameter, and (C) flow-mediated dilation (FMD). Patients with COPD underwent two examinations during 2 different days (at least I week after first visit) to confirm within-day reproducibility of endothelial function. The x-axis shows the mean of each variable and the $\mathrm{x}$-axis the difference between pairs. Solid lines represent systematic bias and dashed lines represent the $95 \% \mathrm{Cl}$ at two SD of the differences. 
Table 3 Within-day (session A vs session B) and between-day (session A vs session C) reproducibility of arterial stiffness

\begin{tabular}{|c|c|c|c|c|c|c|c|c|c|c|c|c|c|c|c|}
\hline \multirow[t]{2}{*}{ Variable } & \multirow{2}{*}{$\begin{array}{l}\text { Session A } \\
n=17\end{array}$} & \multirow{2}{*}{$\begin{array}{l}\text { Session B } \\
n=17\end{array}$} & \multirow{2}{*}{$\begin{array}{l}\text { Session C } \\
n=17\end{array}$} & \multicolumn{6}{|c|}{ Within-day session A vs session B } & \multicolumn{6}{|c|}{ Between-day session A vs session C } \\
\hline & & & & $\begin{array}{l}\text { Paired } \\
\text { t-test* }\end{array}$ & $\mathbf{C V}^{*}$ & $\mathrm{CV}^{\prime *}$ & ICC* & $r^{*}$ & $\begin{array}{l}\text { BA } \\
\text { plot* }\end{array}$ & $\begin{array}{l}\text { Paired } \\
t \text {-test* }\end{array}$ & $\mathbf{C V}^{*}$ & $\mathrm{CV}^{\prime *}$ & ICC* & $r^{*}$ & $\begin{array}{l}\text { BA } \\
\text { plot* }\end{array}$ \\
\hline Alx (\%) & $3 I \pm 2$ & $33 \pm 2$ & $31 \pm 3$ & 0.14 & 9.88 & 2.3 & $\begin{array}{l}\mathbf{0 . 8 8 7} \\
P<0.01\end{array}$ & $\begin{array}{l}0.797 \\
P<0.01\end{array}$ & $\mathbf{x}$ & 0.96 & 10.4 & 2.3 & $\begin{array}{l}\mathbf{0 . 8 6 2} \\
P<0.01\end{array}$ & $\begin{array}{l}\mathbf{0 . 7 6 I} ; \\
\mathbf{P}<0.01\end{array}$ & $x$ \\
\hline Alx75 (\%) & $33 \pm 2$ & $32 \pm 3$ & $31 \pm 2$ & 0.60 & 11.3 & 2.3 & $\begin{array}{l}\mathbf{0 . 8 4 7} \\
P<0.01\end{array}$ & $\begin{array}{l}0.749 \\
P<0.0 \text { I }\end{array}$ & $\mathbf{x}$ & 0.32 & 9.27 & 2.1 & $\begin{array}{l}\mathbf{0 . 8 7 3} \\
\mathbf{P}<0.0 \mathrm{I}\end{array}$ & $\begin{array}{l}\mathbf{0 . 7 7 8} \\
P<0.01\end{array}$ & $x$ \\
\hline $\begin{array}{l}\text { PWV } \\
(\mathrm{m} / \mathrm{s})\end{array}$ & $8.6 \pm 0.9$ & $8.8 \pm 0.9$ & $8.5 \pm 0.7$ & 0.37 & 2.74 & 0.2 & $\begin{array}{l}0.988 \\
P<0.01\end{array}$ & $\begin{array}{l}0.979 \\
P<0.01\end{array}$ & $\mathbf{x}$ & 0.70 & 4.68 & 0.4 & $\begin{array}{l}\mathbf{0 . 9 6 3} \\
P<0.01\end{array}$ & $\begin{array}{l}\mathbf{0 . 9 2 9} \\
P<0.01\end{array}$ & $x$ \\
\hline
\end{tabular}

Notes: The arterial stiffness variables assessed in this study show a high reproducibility both during the same session and during different sessions in patients with COPD. All the variables analyzed meet six out of the six criteria required to confirm reproducibility. Data are expressed as mean \pm standard error of mean. Paired $t$-test statistic ( $P$-value), coefficient of variation $(\mathrm{CV}=\mathrm{SD} /$ mean $\times 100)$; coefficient of variation prime $\left(\mathrm{CV}^{\prime}=[100 \times \mathrm{SD}] /[\right.$ mean +100$\left.]\right)$; intra-class correlation coefficient $(\mathrm{ICC})$; Pearson's correlation coefficients $(r)$; $\mathrm{X}$ in the Bland-Altman plot (BA plot) cell indicates acceptable plot. * indicated acceptable reproducibility. Individual reproducibility assessments that meet the criteria are in bold.

Abbreviations: Alx, augmentation index; PWV, pulse wave velocity.

is the first study to investigate reproducibility of the FMD test in patients with COPD.

The present findings document similar average values for within-day (sessions A and B) and between-day (sessions A and C) reproducibility assessments. In fact, the overall differences between means are considerably lower than the acceptable reproducibility value previously proposed by Corretti et al. ${ }^{29}$ In addition, we report reproducibility assessments of CV, $\mathrm{CV}^{\prime}$, Pearson correlation coefficients, ICC, and Bland-Altman plots. In the current study, the mean $\mathrm{CV}_{\mathrm{FMD}}$ reported for within-day and between-day reproducibility is $31 \%$ and $38 \%$, respectively. However, it has to be noted that the expression of FMD as a percentage makes the data very sensitive to small changes. In fact, the range of $\mathrm{CV}$ described in the literature for FMD varies from $2 \%$ to $84 \%{ }^{40}$ with acceptable overall FMD variations of $35 \% \%^{22,29}$ indicating reproducibility. ${ }^{22,29}$ In addition, utilizing a $\mathrm{CV}^{\prime}$ criteria of $<3 \%$ for determining reproducibility of FMD (\%) over time is considered acceptable. ${ }^{29}$ In an effort to not only create a robust assessment, but also reinforce the within-day and between-day reproducibility of endothelial function in patients with COPD, the present study included ICC as a reliability parameter, and Bland-Altman plots as a way to estimate the $95 \%$ limits of agreement between measurements. The statistically significant and high ICC values reported here constitute reliability in endothelial function within-day and between-day. Additionally, the Bland-Altman plots emphasize the general concept of agreement supported by the other FMD reproducibility indices, both in the same day and on different days. Collectively, our findings provide evidence that assessment of endothelial function using the FMD test is reproducible within the same day as well as between days in patients with COPD.

It is worth noting that, in spite of the increasing interest in this technique, several practical challenges affect the reproducibility of this method, restricting its clinical use. ${ }^{37}$ Expensive equipment, high technical standardization, considerable sonographer experience, and a precise analysis of the images have limited a wider application of this technique. For those reasons, we have been consistent with the technical aspects of the FMD method by following the recommendations for the ultrasonic assessment of $\mathrm{FMD}^{22}$ to minimize both physiological and technical concerns that influence validity and reproducibility of this procedure. Hence, to avoid variability in the FMD technique and get reliable results presented here, a highly-skilled operator had performed all the analysis, utilizing arterial images to identify internal landmarks and the same arterial segment in each participant throughout the three sessions of the present investigation. We also believe that the use of a stereotactic probe-holder and an automatic software analysis system (Brachial Analyzer Software) have reduced the variability of the FMD test.

Aside from the technical aspects, the instability of the brachial artery dilation has been also related with the spontaneous changes of the arterial walls. Those variations not only impact the hyperemic response, but introduce fluctuations in blood pressure, blood flow, blood viscosity, and arterial stiffness, ${ }^{30,41}$ all of which can potentially increase the variability of the FMD technique. For that reason, to rule out the interference of other possible factors in the FMD reproducibility assessment and make the present results more robust, we also considered the inclusion of other FMD-related parameters such as baseline and peak diameters. ${ }^{22}$ Accordingly, these additional results not only complement, but reinforce the low variation of FMD within the same day and between-days and confirm reproducibility.

\section{Reproducibility of arterial stiffness}

There is a link between vascular endothelial function and arterial stiffness ${ }^{42-44}$ that is mainly due to a degeneration of 
the media, an increase in collagen content, and a decrease in vascular dispensability. ${ }^{10}$ Similar to the FMD test for the assessment of endothelial function, arterial stiffness has also been shown to predict cardiovascular events ${ }^{10}$ as well as disease severity in patients with COPD. ${ }^{45}$ In addition, central arterial stiffness (AIx) has been associated with the severity of airway obstruction during COPD exacerbations $s^{4,46}$ and there has been increasing utilization of measuring AIx and PWV to assess arterial stiffness over time in patients with COPD. ${ }^{10,18,19,28}$ The reproducibility of arterial stiffness in patients with COPD; however, has yet to be investigated until now.

No differences in AIx, AIx75, or PWV were observed between sessions $\mathrm{A}$ and $\mathrm{B}$ or between sessions $\mathrm{A}$ and $\mathrm{C}$. Additionally, we report acceptable $\mathrm{CV}, \mathrm{CV}^{\prime}$, Pearson correlation coefficients, and ICC for all arterial stiffness variables. Furthermore, the Bland-Altman plots emphasize the agreement of AIx, AIx75, or PWV on multiple testing sessions (Figures S1 and S2). Collectively, the present data indicate within-day and between-day reproducibility of arterial stiffness in patients with COPD.

There are many different factors that can impact and limit the reproducibility assessment of both endothelial function and arterial stiffness including sex, age and race. ${ }^{20,29,30}$ Specific to patients with COPD, pulmonary exacerbation and smoking can impact endothelial function and arterial stiffness. ${ }^{47}$ In order to rule out the possible effects of these variables on our results, an ANCOVA was performed with age, sex and race as covariates. Additionally, we have also included the possible effects of two major metabolites of nicotine (cotinine and trans-3-hydroxycotinine) ${ }^{48}$ as covariates due to the close relationship among continued tobacco use and worsening prognosis of COPD. ${ }^{49}$ The covariate analyses confirmed that neither of the aforementioned factors influenced the conclusion of within-day or between-day reproducibility of endothelial function or arterial stiffness in patients with COPD.

\section{Clinical perspectives}

Patients with COPD often present with cardiovascular disease, likely related to impaired vascular health and function which lead to a high mortality and morbidity among this patient population. Based on this fact, addressing cardiovascular risk in patients with COPD could improve their survival rate. In this line and for the first time, the present study has provided a robust assessment of within-day and between-day reproducibility of both endothelial function and arterial stiffness in patients with COPD. Assessments of endothelial function met at least five out of the six reproducibility criteria, whereas six out of six criteria were met for arterial stiffness. Our findings corroborate previous conducted studies in patients with COPD that have utilized FMD and PWV. Perhaps more importantly, FMD and arterial tonometry represent novel, non-invasive methods that can be utilized to evaluate the impact of therapeutic interventions on cardiovascular disease risk in patients with COPD.

\section{Acknowledgments}

The authors would like to thank the patients for their commitment and participation in this study. We also would like to acknowledge Dr Betty Wray for her support in patient recruitment to this study. This study was supported by the American Heart Association 10SDG3050006 (RAH).

\section{Authors' contributions}

RAH conceived and designed the study; NS, LB, and RAH performed experiments; PR-M and RAH analyzed data, interpreted the results of experiments, prepared figures, and drafted the manuscript; PR-M, NS, LB, TD, and RAH edited and revised the manuscript and provided final approval; and RAH is the guarantor of the final version of the manuscript. All authors contributed toward data analysis, drafting, and revising the manuscript.

\section{Disclosure}

The authors report no conflicts of interest in this work.

\section{References}

1. Qureshi H, Sharafkhaneh A, Hanania NA. Chronic obstructive pulmonary disease exacerbations: latest evidence and clinical implications. Ther $A d v$ Chronic Dis. 2014;5(5):212-227.

2. Eickhoff P, Valipour A, Kiss D, et al. Determinants of systemic vascular function in patients with stable chronic obstructive pulmonary disease. Am J Respir Crit Care Med. 2008;178(12):1211-1218.

3. Schunemann HJ, Dorn J, Grant BJ, Winkelstein W Jr, Trevisan M. Pulmonary function is a long-term predictor of mortality in the general population: 29-year follow-up of the Buffalo Health Study. Chest. 2000; 118(3):656-664.

4. Patel AR, Kowlessar BS, Donaldson GC, et al. Cardiovascular risk, myocardial injury, and exacerbations of chronic obstructive pulmonary disease. Am J Respir Crit Care Med. 2013;188(9):1091-1099.

5. Anthonisen NR, Connett JE, Enright PL, Manfreda J. Hospitalizations and mortality in the Lung Health Study. Am J Respir Crit Care Med. 2002; 166(3):333-339.

6. Takahashi T, Kobayashi S, Fujino N, et al. Increased circulating endothelial microparticles in COPD patients: a potential biomarker for COPD exacerbation susceptibility. Thorax. 2012;67(12):1067-1074.

7. Clarenbach CF, Senn O, Sievi NA, et al. Determinants of endothelial function in patients with COPD. Eur Respir J. 2013;42(5):1194-1204.

8. Halcox JP, Donald AE, Ellins E, et al. Endothelial function predicts progression of carotid intima-media thickness. Circulation. 2009;119(7): 1005-1012.

9. Yeboah J, Crouse JR, Hsu FC, Burke GL, Herrington DM. Brachial flow-mediated dilation predicts incident cardiovascular events in older adults: the Cardiovascular Health Study. Circulation. 2007;115(18) 2390-2397. 
10. Vivodtzev I, Tamisier R, Baguet JP, Borel JC, Levy P, Pepin JL. Arterial stiffness in COPD. Chest. 2014;145(4):861-875.

11. Ghiadoni L, Magagna A, Versari D, et al. Different effect of antihypertensive drugs on conduit artery endothelial function. Hypertension. 2003;41(6):1281-1286.

12. Plantinga Y, Ghiadoni L, Magagna A, et al. Supplementation with vitamins $\mathrm{C}$ and $\mathrm{E}$ improves arterial stiffness and endothelial function in essential hypertensive patients. Am J Hypertens. 2007;20(4):392-397.

13. Charakida M, Masi S, Loukogeorgakis SP, Deanfield JE. The role of flow-mediated dilatation in the evaluation and development of antiatherosclerotic drugs. Curr Opin Lipidol. 2009;20(6):460-466.

14. Hadi HA, Carr CS, Al Suwaidi J. Endothelial dysfunction: cardiovascular risk factors, therapy, and outcome. Vasc Health Risk Manag. 2005;1(3):183-198.

15. Brunner H, Cockcroft JR, Deanfield J, et al. Endothelial function and dysfunction. Part II: Association with cardiovascular risk factors and diseases. A statement by the Working Group on Endothelins and Endothelial Factors of the European Society of Hypertension. $J$ Hypertens. 2005;23(2):233-246.

16. Ozben B, Eryuksel E, Tanrikulu AM, Papila-Topal N, Celikel T, Basaran Y. Acute exacerbation impairs endothelial function in patients with chronic obstructive pulmonary disease. Turk Kardiyol Dern Ars. 2010; 38(1):1-7.

17. Barr RG, Mesia-Vela S, Austin JH, et al. Impaired flow-mediated dilation is associated with low pulmonary function and emphysema in ex-smokers: the Emphysema and Cancer Action Project (EMCAP) Study. Am J Respir Crit Care Med. 2007;176(12):1200-1207.

18. Ives SJ, Harris RA, Witman MA, et al. Vascular dysfunction and chronic obstructive pulmonary disease: the role of redox balance. Hypertension. 2014;63(3):459-467.

19. Vivodtzev I, Minet C, Tamisier R, et al. Arterial stiffness by pulse wave velocity in COPD: reliability and reproducibility. Eur Respir J. 2013; 42(4):1140-1142.

20. Donald AE, Halcox JP, Charakida M, et al. Methodological approaches to optimize reproducibility and power in clinical studies of flowmediated dilation. J Am Coll Cardiol. 2008;51(20):1959-1964.

21. No authors listed. Standards for the diagnosis and care of patients with chronic obstructive pulmonary disease. American Thoracic Society. Am J Respir Crit Care Med. 1995;152(5 Pt 2):S77-S121.

22. Harris RA, Nishiyama SK, Wray DW, Richardson RS. Ultrasound assessment of flow-mediated dilation. Hypertension. 2010;55(5): $1075-1085$.

23. Wilkinson IB, MacCallum H, Flint L, Cockcroft JR, Newby DE, Webb DJ. The influence of heart rate on augmentation index and central arterial pressure in humans. $J$ Physiol. 2000;525 Pt 1:263-270.

24. Laurent S, Cockcroft J, Van Bortel L, et al. Expert consensus document on arterial stiffness: methodological issues and clinical applications. Eur Heart J. 2006;27(21):2588-2605.

25. Roberts CK, Lee MM, Katiraie M, et al. Strength fitness and body weight status on markers of cardiometabolic health. Med Sci Sports Exerc. 2015;47(6):1211-1218.

26. Herrington DM, Fan L, Drum M, et al. Brachial flow-mediated vasodilator responses in population-based research: methods, reproducibility and effects of age, gender and baseline diameter. J Cardiovasc Risk. 2001;8(5):319-328.

27. Guzik TJ, Grodzicki T. "Radical" link between chronic obstructive pulmonary disease and cardiovascular disease? Hypertension. 2014;63(3): 444-446.

28. Maclay JD, McAllister DA, Mills NL, et al. Vascular dysfunction in chronic obstructive pulmonary disease. Am J Respir Crit Care Med.2009; 180(6):513-520.

29. Corretti MC, Anderson TJ, Benjamin EJ, et al. Guidelines for the ultrasound assessment of endothelial-dependent flow-mediated vasodilation of the brachial artery: a report of the International Brachial Artery Reactivity Task Force. J Am Coll Cardiol. 2002;39(2):257-265.
30. Harris RA, Padilla J, Hanlon KP, Rink LD, Wallace JP. Reproducibility of the flow-mediated dilation response to acute exercise in overweight men. Ultrasound Med Biol. 2007;33(10):1579-1585.

31. Celermajer DS, Sorensen KE, Gooch VM, et al. Non-invasive detection of endothelial dysfunction in children and adults at risk of atherosclerosis. Lancet. 1992;340(8828):1111-1115.

32. Anderson TJ, Uehata A, Gerhard MD, et al. Close relation of endothelial function in the human coronary and peripheral circulations. $\mathrm{J} \mathrm{Am} \mathrm{Coll}$ Cardiol. 1995;26(5):1235-1241.

33. Welsch MA, Allen JD, Geaghan JP. Stability and reproducibility of brachial artery flow-mediated dilation. Med Sci Sports Exerc. 2002; 34(6):960-965.

34. Harris RA, Padilla J, Rink LD, Wallace JP. Variability of flow-mediated dilation measurements with repetitive reactive hyperemia. Vasc Med. 2006;11(1):1-6.

35. Hijmering ML, Stroes ES, Pasterkamp G, Sierevogel M, Banga JD, Rabelink TJ. Variability of flow mediated dilation: consequences for clinical application. Atherosclerosis. 2001;157(2):369-373.

36. De Roos NM, Bots ML, Schouten EG, Katan MB. Within-subject variability of flow-mediated vasodilation of the brachial artery in healthy men and women: implications for experimental studies. Ultrasound Med Biol. 2003;29(3):401-406.

37. Charakida M, de Groot E, Loukogeorgakis SP, et al. Variability and reproducibility of flow-mediated dilatation in a multicentre clinical trial. Eur Heart J. 2013;34(45):3501-3507.

38. Ghiadoni L, Faita F, Salvetti M, et al. Assessment of flow-mediated dilation reproducibility: a nationwide multicenter study. J Hypertens. 2012;30(7):1399-1405.

39. Kanahara M, Harada H, Katoh A, Ikeda H. New methodological approach to improve reproducibility of brachial artery flow-mediated dilatation. Echocardiography. 2014;31(2):197-202.

40. Woodman RJ, Playford DA, Watts GF, et al. Improved analysis of brachial artery ultrasound using a novel edge-detection software system. J Appl Physiol (1985). 2001;91(2):929-937.

41. Thijssen DH, Black MA, Pyke KE, et al. Assessment of flow-mediated dilation in humans: a methodological and physiological guideline. $\mathrm{Am}$ J Physiol Heart Circ Physiol. 2011;300(1):H2-H12.

42. Naka KK, Tweddel AC, Doshi SN, Goodfellow J, Henderson AH. Flow-mediated changes in pulse wave velocity: a new clinical measure of endothelial function. Eur Heart J. 2006;27(3):302-309.

43. Kinlay S, Creager MA, Fukumoto M, et al. Endothelium-derived nitric oxide regulates arterial elasticity in human arteries in vivo. Hypertension. 2001;38(5):1049-1053.

44. Wilkinson IB, Qasem A, McEniery CM, Webb DJ, Avolio AP, Cockcroft JR. Nitric oxide regulates local arterial distensibility in vivo. Circulation. 2002;105(2):213-217.

45. Lee HM, Lee J, Lee K, Luo Y, Sin DD, Wong ND. Relation between COPD severity and global cardiovascular risk in US adults. Chest. 2012;142(5):1118-1125.

46. Albu A, Fodor D, Bondor C, Suciu O. Carotid arterial stiffness in patients with chronic obstructive pulmonary disease. Acta Physiol Hung. 2011;98(2):117-127.

47. Maclay JD, MacNee W. Cardiovascular disease in COPD: mechanisms. Chest. 2013;143(3):798-807.

48. Llaquet H, Pichini S, Joya X, et al. Biological matrices for the evaluation of exposure to environmental tobacco smoke during prenatal life and childhood. Anal Bioanal Chem. 2010;396(1):379-399.

49. Zuo L, He F, Sergakis GG, et al. Interrelated role of cigarette smoking, oxidative stress, and immune response in COPD and corresponding treatments. Am J Physiol Lung Cell Mol Physiol. 2014;307(3): L205-L218. 


\section{Supplementary materials \\ Methodology \\ Pulmonary function testing}

A minimum of three reproducible trials were completed by each participant, and the best of three acceptable forced expiratory maneuvers were selected to represent the pulmonary function values. The National Health and Nutrition Examination Survey (NHANES) III spirometric reference standards were used to determine the percentage predicted data set.

\section{Brachial artery flow-mediated dilation}

Endothelial function was determined via brachial artery flowmediated dilation (FMD) in accordance with the tutorial on the ultrasound assessment of FMD. ${ }^{1}$ Briefly, measurements took place in a quiet, temperature-controlled $\left(22^{\circ} \mathrm{C}-24^{\circ} \mathrm{C}\right)$ room, where patients were instructed to lie supine with their right arm laterally extended for 20 minutes to establish a hemodynamic steady state. The brachial artery was imaged longitudinally in Duplex mode (simultaneous B-mode and blood velocity profiles) by a Doppler ultrasound (Logiq 7; GE Medical Systems, Milwaukee, WI, USA) using a 12-MHz linear transducer placed $2 \mathrm{~cm}$ to $10 \mathrm{~cm}$ above the antecubital fossa. Blood velocity was obtained with the sample volume set at a depth between $1 \mathrm{~cm}$ and $3 \mathrm{~cm}$. The average diameter and blood velocity for 30 cardiac cycles were recorded and analyzed to represent baseline values. Subsequently, a $5 \mathrm{~cm} \times 84 \mathrm{~cm}$ forearm occlusion cuff (D.E. Hokanson, Bellevue, WA, USA) was placed immediately distal to the medial epicondyle and rapidly inflated to $250 \mathrm{mmHg}$ for 5 minutes (E-20 rapid cuff inflator; D.E. Hokanson) to induce arterial occlusion and reactive hyperemia of the brachial artery. ECG gaiting (Accusync 72; Accusync Medical Research, Milford, CT, USA) was used to capture end-diastolic arterial diameters, triggered by the QRS complex, for automated offline analysis of brachial artery vasodilatation (Brachial Analyzer Software, Medical Imaging Applications, Coralville, IA, USA). FMD is expressed as a percent increase in peak diameter from baseline diameter.

\section{Arterial tonometry \\ Pulse wave analysis}

Augmentation index (Aix) was determined by applanation tonometry (SphygmoCor; AtCor Medical, West Ryde, NSW, Australia) of the left radial artery, calibrated with the brachial systolic and diastolic pressure measured with an inflated cuff at the brachial artery in accordance with the manufacturer's recommendations. The SphygmoCor system transforms the peripheral waveform to a central waveform using a mathematical algorithm. Since AIx varies with heart rate, it is usually adjusted to 75 beats per minute (AIx75). ${ }^{2}$ At least two independent waveform analyses were obtained from each subject, with reproducible measurements only accepted on meeting SphygmoCor quality control criteria.

\section{Pulse wave velocity}

Carotid-femoral pulse wave velocity (cfPWV) was determined in duplicate using the SphygmoCor system by sequentially recording electrocardiographic-gated carotid and femoral artery waveforms by applanation tonometry as described previously. ${ }^{3,4}$ Using a Rosscraft segmometer, straight line distance measurements were taken from the suprasternal notch to the carotid sampling site and from the suprasternal notch to the site where the femoral artery was measured. The time interval ( $t$, in seconds) between the onset of femoral and carotid waveforms was determined as the mean from 10 consecutive cardiac cycles. High quality measurements were confirmed by the standard deviation of time intervals corresponding to the patient's ECG and
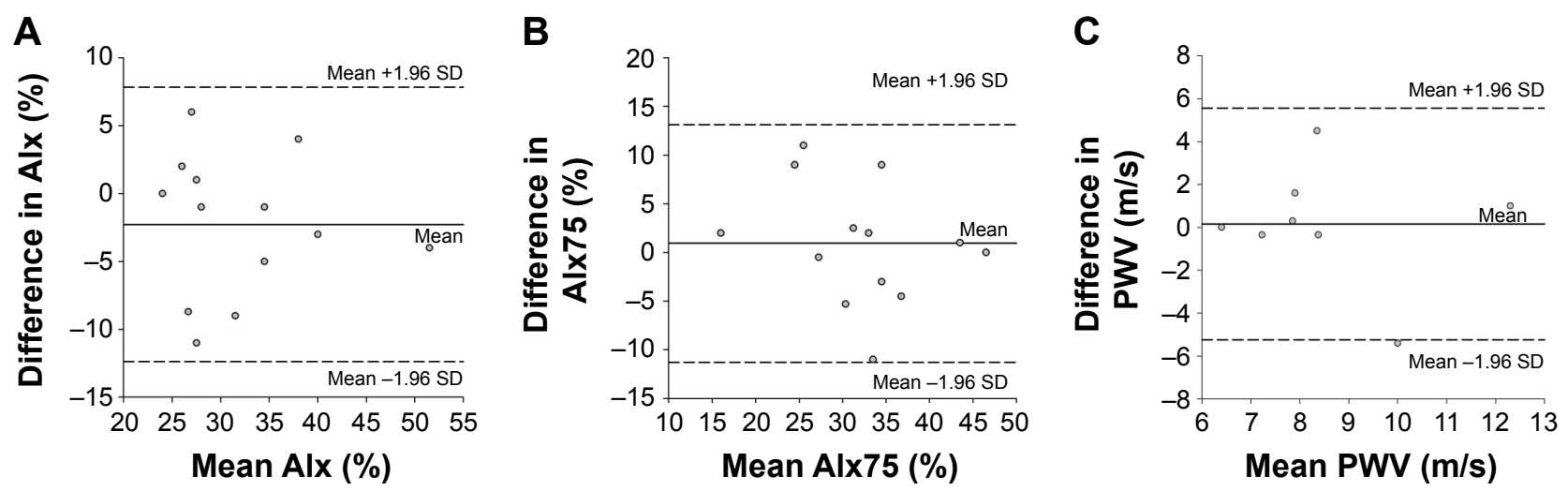

Figure SI Bland-Altman analysis plots illustrating no systematic bias and good within-day reproducibility for (A) Alx, (B) Alx75, and (C) PWV.

Notes: Solid lines represent systematic bias and dashed lines represent the $95 \% \mathrm{Cl}$ at two SD of the differences.

Abbreviations: Alx, augmentation index; PWV, pulse wave velocity; Alx75, Alx at 75 bpm. 

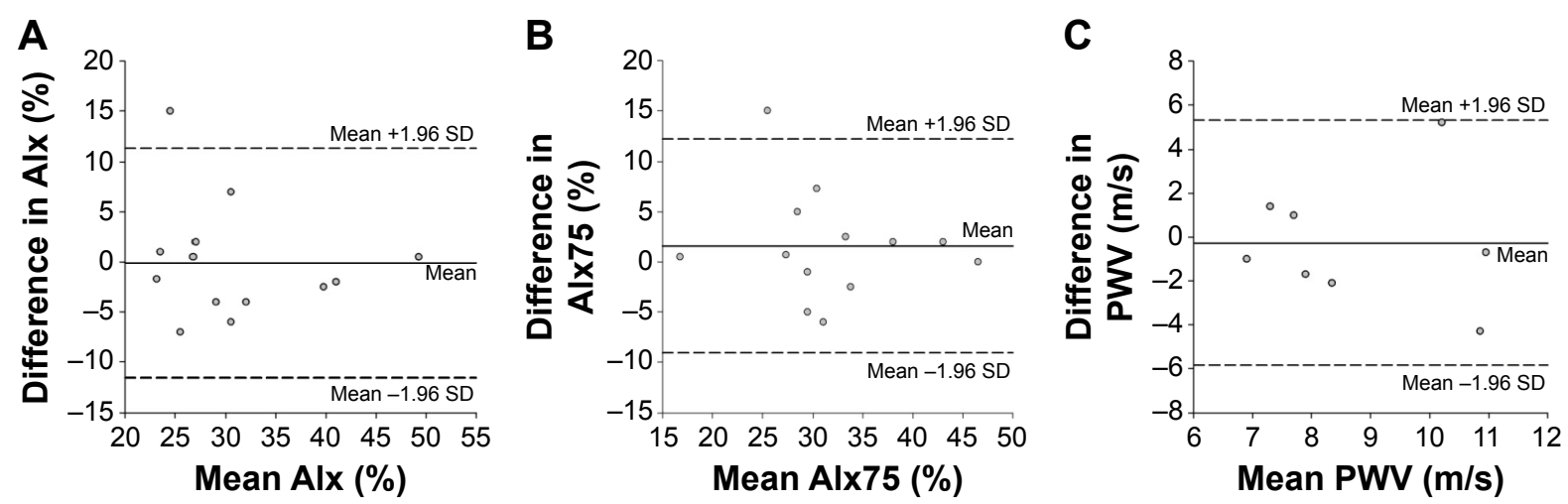

Figure S2 Bland-Altman analysis plots illustrating no systematic bias and good between-day reproducibility for (A) Alx, (B) Alx75, and (C) PWV. Note: Solid lines represent systematic bias and dashed lines represent the $95 \% \mathrm{Cl}$ at two SD of the differences.

Abbreviations: Alx, augmentation index; PWV, pulse wave velocity; Alx75, Alx at 75 bpm.

femoral and carotid artery waveforms. Standard deviations greater than $10 \%$ of the cfPWV value were not accepted. The cfPWV was calculated from the distance between measurement points $(\mathrm{D}$, in meters) and the measured time delay between the peak of the ECG P-wave and the trough of a waveform $(\mathrm{t})$ as follows: $\mathrm{cfPWV}=\mathrm{D} / \mathrm{t}(\mathrm{m} / \mathrm{sec})$.

\section{References}

1. Harris RA, Nishiyama SK, Wray DW, Richardson RS. Ultrasound assessment of flow-mediated dilation. Hypertension. 2010;55:1075-1085.
2. Wilkinson IB, MacCallum H, Flint L, et al. The influence of heart rate on augmentation index and central arterial pressure in humans. J Physiol. 2000;525 Pt 1:263-270.

3. Laurent S, Cockcroft J, Van Bortel L, et al. Expert consensus document on arterial stiffness: methodological issues and clinical applications. Eur Heart J. 2006;27:2588-2605.

4. Roberts CK, Lee MM, Katiraie M, et al. Strength fitness and body weight status on markers of cardiometabolic health. Med Sci Sports Exerc. 2015; 47:1211-1218.

\section{Publish your work in this journal}

The International Journal of COPD is an international, peer-reviewed journal of therapeutics and pharmacology focusing on concise rapid reporting of clinical studies and reviews in COPD. Special focus is given to the pathophysiological processes underlying the disease, intervention programs, patient focused education, and self management protocols.

\section{Dovepress}

This journal is indexed on PubMed Central, MedLine and CAS. The manuscript management system is completely online and includes a very quick and fair peer-review system, which is all easy to use. Visit $\mathrm{http} / / / \mathrm{www}$.dovepress.com/testimonials.php to read real quotes from published authors. 